\title{
Initial tests of the rubber belts tension of conveyors with a prototype measuring system
}

\author{
Badania wstępne napięcia taśm przenośników \\ z użyciem prototypowego urządzenia pomiarowego
}

\begin{abstract}
Results of initial test of the rubber belts tension of conveyors using with a prototype measuring device are presented. The innovative measuring system consists of two independent tension sensors placed on a passive shaft working in real time. Correct interpretation of the initial data suggests ability to perform real-time diagnostics of the rubber belts condition.
\end{abstract}

KEYWORDS: rubber belts, strain gauges, real-time measurement

Przedstawiono wyniki badań wstępnych napięcia taśmy przenośnika przeprowadzonych na prototypowym urządzeniu pomiarowym. Nowatorski układ badawczy opiera się na dwóch czujnikach tensometrycznych umieszczonych bezpośrednio na wałku biernym przenośnika. Badanie napięcia odbywało się w czasie rzeczywistym. Wstępne wyniki sugerują, że odpowiednia interpretacja danych pozwala zdiagnozować stan taśmy przenośnika.

SŁOWA KLUCZOWE: taśma gumowa, czujniki tensometryczne, pomiar w czasie rzeczywistym

\section{Wprowadzenie}

Transport bliski jest istotnym elementem funkcjonowania zakładu - rzutuje na jego prawidłową pracę. Środkami transportu bliskiego są dźwignice oraz przenośniki. Transport odbywający się w obrębie jednego zakładu pracy nazywamy transportem wewnętrznym lub wewnątrzzakładowym [1]. Współczesne rozwiązania techniczne, mające za zadane kontrolowanie parametrów taśmy przenośnika, opierają się na:

- wykorzystaniu specjalnego układu badawczego odbierającego sygnał z czujników lub układu nadawczo-odbiorczego analizującego przemieszczanie się zatopionych linek, markerów,

- zastosowaniu fal ultradźwiękowych [2] lub magnetycznych i drogich specjalistycznych taśm wyposażonych w czujniki nadawcze, stalowe linki, specjalne markery lub magnesy,

- wysokich kosztach budowy.

Te rozwiązania mają wiele wad pod względem technicznym (taśma stanowi zarówno obiekt badań, jak i integralny element układu badawczego) i ekonomicznym. Uszkodzenie taśmy pozbawia system badawczy źródła informacji i powoduje konieczność za- kupu nowej specjalistycznej i drogiej taśmy, bez której analiza jest niemożliwa.

Analiza stanu wiedzy na temat transportu bliskiego wskazuje na zapotrzebowanie obejmujące opracowanie nowego układu badawczego do pomiaru napięcia taśm przenośników, spełniającego współczesne wymogi konstrukcyjne i użytkowe, z zachowaniem aspektów ekologicznych. Ważne jest prowadzenie racjonalnej gospodarki w zakresie konserwacji czy napraw urządzeń transportujących, do czego konieczne jest opracowanie metody określania rozkładu pracy taśmy przenośnikowej i jej wykorzystania do prognozowania momentu wymiany taśmy tuż przed jej uszkodzeniem, by maksymalnie wydłużyć czas eksploatacji, ale nie dopuścić do awarii [2].

\section{Kierunki badań}

Zgodnie z tendencjami czwartej rewolucji przesyłowej [3], dotyczącymi m.in. eksploatacji i nadzorowania pracy przenośników taśmowych, przyjęto wstępne założenia do opracowania procedury badawczej i urządzenia. Dotychczasowe rozwiązania konstrukcyjne oraz potrzeba zapewnienia bezawaryjnej eksploatacji przenośników taśmowych wyznaczyły główne wymagania co do systemu nadzorującego stan taśmy w czasie pracy i wykrywającego uszkodzenia na wczesnym etapie ich powstawania. W wyniku wstępnych badań przyjęto, że: - zastosowanie czujników tensometrycznych zapewnia wystarczającą dokładność pomiarów napięcia taśmy,

- wprowadzenie bezprzewodowej transmisji danych nie powoduje znacznego zwiększenia niepewności pomiarów i nie wprowadza błędów nadmiernych,

- monitorowanie rozkładu sił nacisku na wałku daje wystarczającą informację pozwalającą na wczesne wykrywanie uszkodzeń.

Wstępne badania przeprowadzono w Laboratorium Automatyzacji Procesów Produkcyjnych na Wydziale Mechanicznym UTH im. K. Puławskiego w Radomiu. $\mathrm{W}$ prototypie urządzenia do kontroli napięcia i zużycia taśm przenośników zastosowano dwa czujniki tensometryczne: CP152NS i CP151AS, oznaczone odpowiednio jako $T_{1}$ oraz $T_{2}$, które umieszczono bezpośrednio na wałku biernym przenośnika (rys. 1) [4].

* Tomasz Ryba, ryba2104@op.pl - UTH im. K. Pułaskiego w Radomiu 


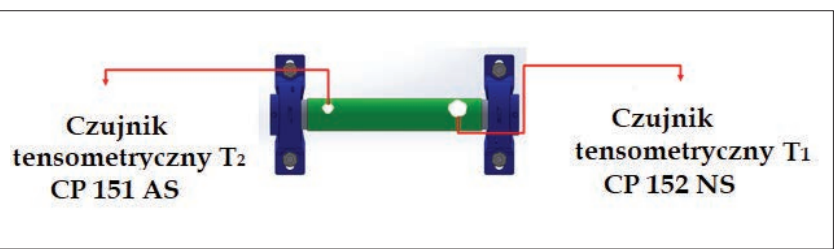

Fig. 1. Placing $T_{1}$ and $T_{2}$ sensors on the deflection shaft Rys. 1. Umieszczenie czujników $T_{1}$ oraz $T_{2}$ na wałku zwrotnym

Znając wartość siły uzyskanej z czujników tensometrycznych i korzystając ze wzoru (1), można uzyskać siłę, jaka działa na układ badawczy w danym punkcie [2]:

$$
F=m \cdot g
$$

gdzie: $F$ - siła odczytana z czujnika [N], g - wartość przyśpieszenie ziemskiego $\left[\mathrm{m} / \mathrm{s}^{2}\right], m-$ masa $[\mathrm{kg}]$ obciążająca czujnik, wywierająca na niego siłę $F$.

Zaproponowany układ doskonale spełnia warunki inteligentnych czujników (cognitive sensor technology), których zadaniem jest połączenie trzech współdziałających podzespołów [5]:

- elementu pomiarowego, który mierzy jeden lub więcej parametrów fizycznych procesu lub obiektu,

- elementu obliczeniowego analizującego wykonywane pomiary,

- interfejsu komunikacyjnego umożliwiającego wymianę informacji z innymi systemami.

\section{Wyniki badań wstępnych}

Do pierwszych rozpoznawczych badań zastosowano dwa różne czujniki w celu określenia stopnia dopasowania do danej aplikacji. Przyjęto, że do badania wstępnego wystarczy analiza sygnałów statycznych, czyli uzyskiwanych przy nieruchomej taśmie w różnych położeniach kątowych wałka. Pomiary wykonano najpierw przy powolnym obracaniu wałka bez obciażenia (rys. 2), a następnie z obciążeniem nieruchomej taśmy masą $0,5 \mathrm{~kg} \mathrm{w}$ dziewięciu różnych punktach na taśmie przenośnika, jak pokazano na rys. 3-5.

Na wykresie (rys. 2) widać, że sygnał pomiarowy siły nacisku występuje tylko w tej części kątowej położenia wałka, w której czujnik znajduje się bezpośrednio

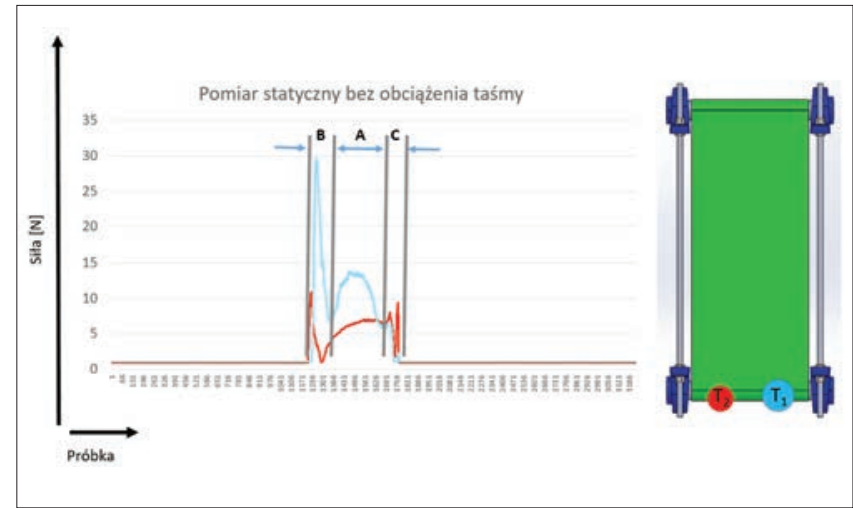

Fig. 2. Indications of $T_{1}$ (blue curve) and $T_{2}$ (red curve) sensors with the belt tensioned without load

Rys. 2. Wskazania czujników $T_{1}$ (niebieska krzywa) i $T_{2}$ (czerwona krzywa) przy napiętej taśmie bez obciążenia pod taśmą. Charakterystyczna jest złożoność wykresu - można wyodrębnić trzy strefy: obszar dość łagodnie zmieniających się wartości nacisku (obszar $A$ ), kiedy cała powierzchnia tensometru jest obciążona, oraz dwa obszary $(B$ i $C$ ) odpowiadające kontaktowi tylko części powierzchni tensometru z taśmą podczas wejścia i wyjścia. Obszary $A, B$ oraz $C$ są widoczne w przypadku obu tensometrów, choć przebieg krzywej siły nacisku jest różny. Zatem, zgodnie ze wzorami (2) i (3), dla przenośnika o średnicach wałka $d=D$ pomiar siły nacisku taśmy na wałek odbywa się w zakresie $\theta=180^{\circ}$ obrotu walka [6].

$$
\begin{aligned}
& \theta_{d}=\pi-2 \sin ^{-1} \frac{D-d}{2 C} \\
& \theta_{D}=\pi-2 \sin ^{-1} \frac{D-d}{2 C}
\end{aligned}
$$

gdzie: $d$ i $D$ to średnice mniejszego i większego wałka $[\mathrm{m}], C$ - odległość między osiami wałków [m], $\theta_{\mathrm{d}}$ i $\theta_{\mathrm{D}}$ - odpowiednio kąty przylegania taśmy do wałków [rad].

Aby łatwo zidentyfikować położenie obciążenia, wyodrębniono trzy strefy: w pobliżu czujników $(A)$, w środkowej części przenośnika $(B)$ i z dala od

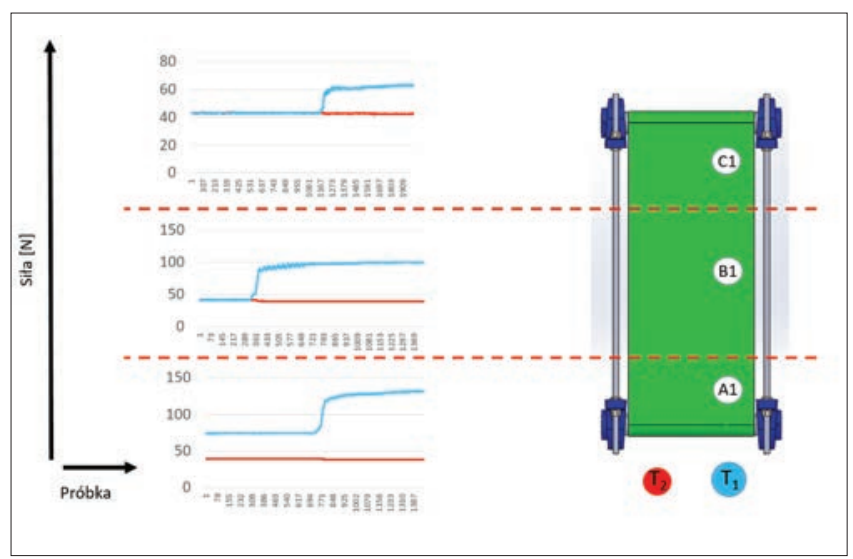

Fig. 3. Indications of $T_{1}$ and $T_{2}$ sensors at a load of $5 \mathrm{~N}$ at points $A 1, B 1, C 1$

Rys. 3. Wskazania czujników $T_{1}$ i $T_{2}$ przy obciążeniu $5 \mathrm{~N}$ w punktach $A 1, B 1, C 1$

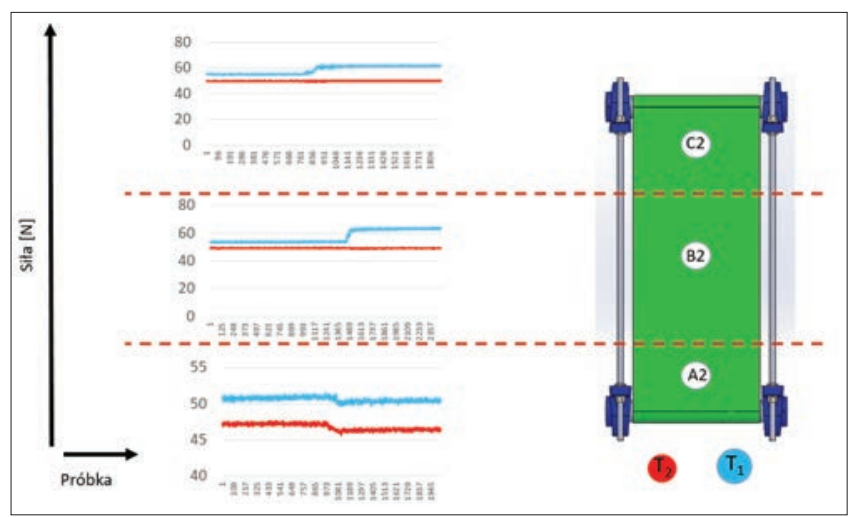

Fig. 4. Indications of $T_{1}$ and $T_{2}$ sensors at a load of $5 \mathrm{~N}$ at points $A 2, B 2, C 2$

Rys. 4. Wskazania czujników $T_{1}$ i $T_{2}$ przy obciążeniu $5 \mathrm{~N}$ w punktach $A 2, B 2, C 2$ 


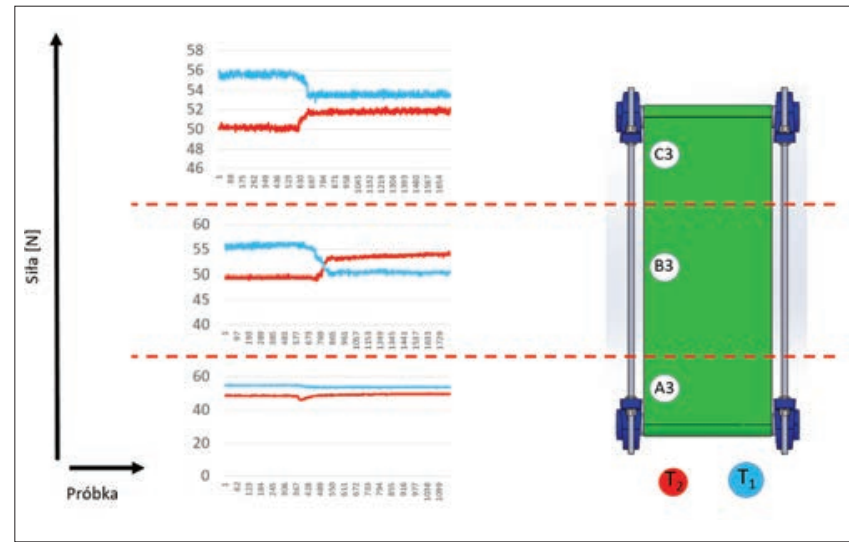

Fig. 5. Indications of $T_{1}$ and $T_{2}$ sensors at a load of $5 \mathrm{~N}$ at points $A 3, B 3, C 3$

Rys. 5 . Wskazania czujników $T_{1}$ i $T_{2}$ przy obciążeniu $5 \mathrm{~N}$ w punktach $A 3, B 3, C 3$

czujników $(C)$. Ponadto zmieniano położenie odważnika w strefie, umieszczając go bliżej krawędzi lub na środku taśmy. Wyniki pomiarów pokazano na rys. 3-5.

Na podstawie analizy wykresów można zauważyć, że czujnik $T_{1}$ praktycznie nie zarejestrował obecności obciążenia w punktach $A 1, B 1, C 1, \mathrm{C} 2$ i $B 2$. Dlatego do dalszych badań urządzenie do kontroli napięcia i zużycia taśm przenośników zostanie wyposażone w jednakowe czujniki typu CP152NS, których liczba została zwiększona do trzech (dodatkowy tensometr umieszczono na środku wałka) [7]. Ze względu na deklarowaną przez producenta liniowość 5\% FS oraz czas ustalenia $<3$ ms uznano, że czujniki te zapewnią wystarczającą dokładność.

Wynik pomiaru to jedynie oszacowanie wartości wielkości mierzonej i dlatego jest on pełny tylko wówczas, gdy poda się niepewność tego oszacowania. W wielu przypadkach wynik pomiaru jest określany na podstawie serii obserwacji otrzymanych $\mathrm{w}$ warunkach powtarzalności. Przyjmuje się, że zmiany wyników powtarzalnych obserwacji wynikają z tego, że wielkości, które mogą mieć wpływ na wynik pomiaru, mają zmienne wartości w czasie dokonywania obserwacji [8]. Dlatego też niezmiernie istotnym punktem kolejnych działań jest oszacowanie niepewności pomiarowej, ale już na bazie finalnego urządzenia, z danymi otrzymanymi z trzech jednakowych czujników tensometrycznych. Taka metodyka badań umożliwi uzyskanie danych ilościowych, charakteryzujących urządzenie do kontroli napięcia i zużycia taśm przenośników przy zminimalizowanym wpływie czynników zakłócających pomiary.

\section{Podsumowanie}

Wnioski wyciągnięte ze wstępnych badań pozwolą na ulepszenie układu badającego i opracowanie metodyki dalszych prac badawczych. Zgodnie z zasadami planowania eksperymentów przyjęto, że do określenia przydatności nowego urządzenia do kontroli napięcia i zużycia taśm przenośników konieczne są: - skalibrowanie czujników tensometrycznych wmontowanych w wałek,
- wykonanie wstępnego napięcia taśmy, by uzyskać jednakowy nacisk na czujniki,

- sprawdzenie stabilności wskazań w warunkach statycznych poprzez powtórzenie pomiarów w określonych odstępach czasu,

- wykonanie serii powtórzeń pomiarów w warunkach obciążenia statycznego,

- ocena powtarzalności wskazań w warunkach statycznych,

- ocena powtarzalności wskazań w warunkach dynamicznych bez obciążenia, przy różnych prędkościach posuwu taśmy,

- ocena stabilności w pomiarach dynamicznych poprzez powtórzenie pomiarów w określonych odstępach czasu,

- test wykrywalności obciążenia taśmy (pomiary $\mathrm{z}$ umieszczeniem odważnika na poruszającej się taśmie),

- test z uszkodzeniem taśmy.

Oprócz tego zostaną zebrane dane jakościowe dotyczące pracy przenośnika taśmowego $\mathrm{w}$ warunkach rzeczywistych, kiedy na wynik pomiaru wpływają liczne czynniki zewnętrzne (np. dynamika umieszczania ładunków na taśmie) i wewnętrzne (np. stan naprężeń wewnątrz taśmy i wynikające $\mathrm{z}$ nich dynamiczne zmiany nacisków na czujnik). Te działania pozwolą określić możliwości pomiarowe urządzenia do kontroli napięcia i zużycia taśm w czasie rzeczywistym. Jednocześnie możliwe będzie wprowadzenie ograniczeń w interpretacji i wykorzystaniu pozyskiwanych sygnałów pomiarowych. Będzie to bazą do opracowania kierunków dalszych badań, dotyczących sterowania procesami monitorowanymi za pomocą badanego urządzenia.

\section{LITERATURA}

[1] Zieliński Z. „Dźwignice i urządzenia transportowe”. Warszawa: Państwowe Wydawnictwo Szkolnictwa Zawodowego, 1970.

[2] Mazurkiewicz D. „Studium wybranych aspektów diagnostyki eksploatacyjnej transportu taśmowego". Lublin: Politechnika Lubelska, 2011.

[3] Bag S., Gupta Sh., Kumar S. "Industry 4.0 adoption and 10R advance manufacturing capabilities for sustainable development". International Journal of Production Economics. 231 (2020): 107844, https://doi.org/10.1016/ j.ijpe.2020.107844.

[4] Ryba T. „Przegląd metod badań napięcia taśm gumowych w przenośnikach taśmowych wykorzystywanych w transporcie bliskim". Mechanik. 3 (2019): 210, https://doi. org/10.17814/mechanik.2019.3.28.

[5] Szulewski P. „Integracja informatyczna kluczowym aspektem środowiska wytwórczego w Przemyśle 4.0". Mechanik. 8-9 (2018): 630-636, https://doi.org/10.17814/mechanik.2018.8-9.100.

[6] Childs P.R.N. "Mechanical Design Engineering Handbook"”. Amsterdam: Elsevier Ltd. (2014).

[7] Ryba T. „Metodyka badań urządzenia do kontroli napięcia i zużycia taśm gumowych w przenośnikach"'. Rozprawa doktorska (niepublikowana). Radom: UTH w Radomiu (2020).

[8] Adamczak S. „Podstawy metrologii $i$ inżynierii jakości dla mechaników”. Warszawa: Wydawnictwo Naukowo-Techniczne (2010). 